\title{
Radiological and non-radiological leaching assessment of alkali-activated materials containing ground granulated blast furnace slag and phosphogypsum
}

Katrijn GIJBELS ${ }^{1}$, Sheldon LANDSBERGER ${ }^{2}$, Pieter SAMYN³ , Remus Ion IACOBESCU ${ }^{4}$, Yiannis PONTIKES ${ }^{4}$, Sonja SCHREURS ${ }^{1}$, Wouter SCHROEYERS ${ }^{1}$

1 Hasselt University, CMK, Nuclear Technology Centre, Agoralaan Gebouw H, 3590 Diepenbeek, Belgium

2 Nuclear Engineering Teaching Lab, University of Texas at Austin, Pickle Research Campus, Austin, TX 78712, USA

3 Hasselt University, IMO, Applied and Analytical Chemistry, Agoralaan Gebouw D, 3590 Diepenbeek, Belgium

4 KU Leuven, Department of Materials Engineering, Kasteelpark Arenberg 44, 3001 Leuven, Belgium

Introduction and experimental set-up

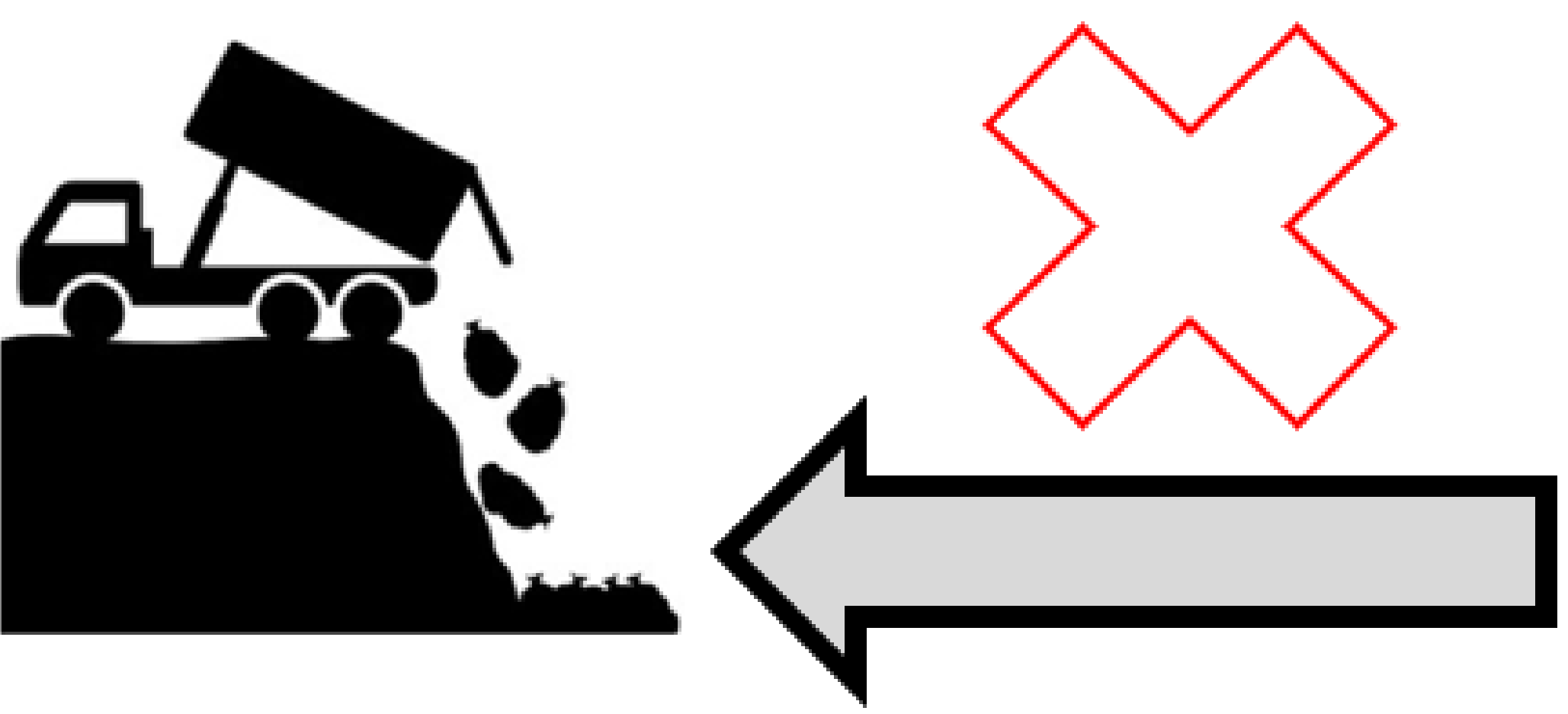

Reuse of industrial by-products or residues for construction materials

Compared with guidelines from European Drinking Water Directive

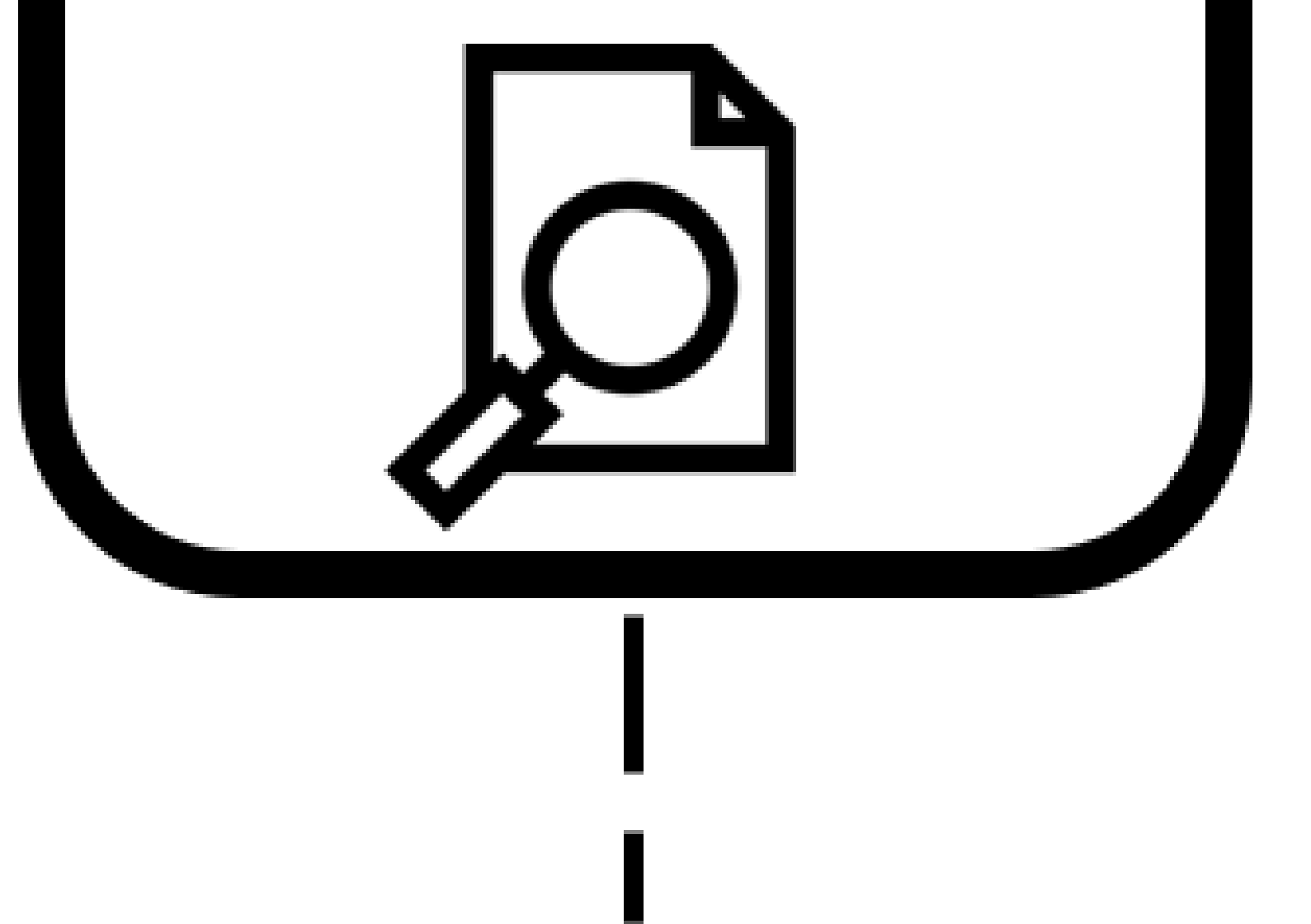

Gamma spectroscopy and neutron activation analysis

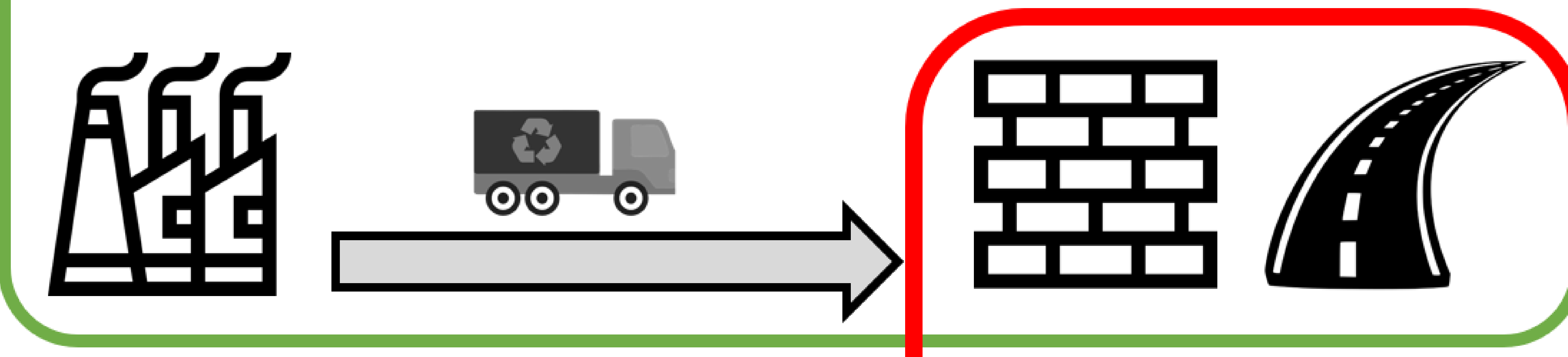

ion-chromatography
Assessment with column leaching test
Release of hazardous compounds to

the environment:

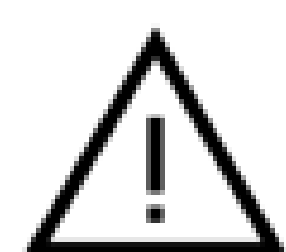

1. Heavy metals

2. Naturally occurring radionuclides

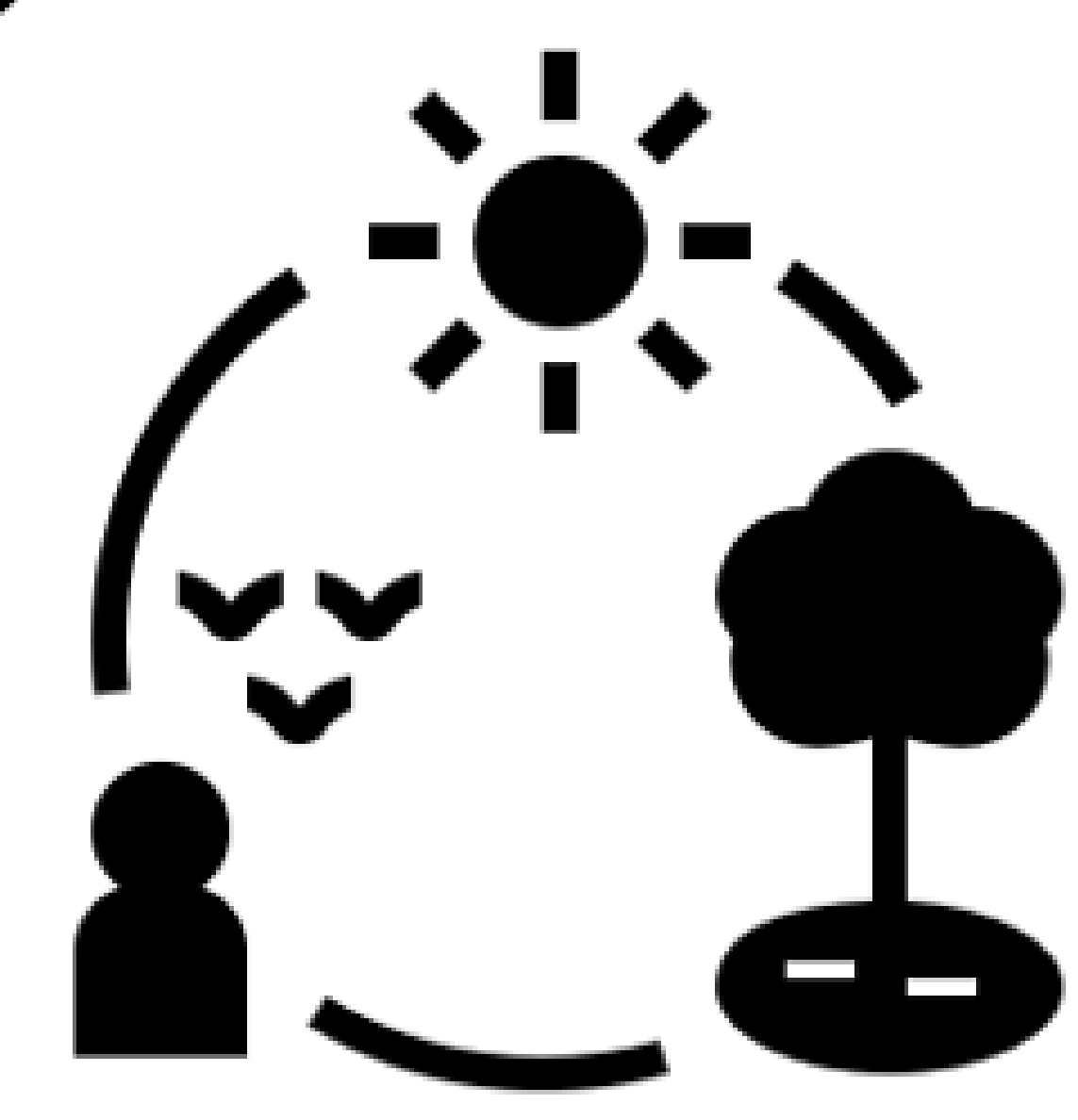

\section{Results and conclusions}

- Naturally occurring radionuclides (NOR) from phosphogypsum can enter the environment by leaching

- Disequilibrium in the ${ }^{238} \mathrm{U}$ and ${ }^{232} \mathrm{Th}$ decay chains due to industrial processing

- Assessment of NOR with a half-life long enough to behave independently in the environment

- Combination of gamma spectroscopy and neutron activation analysis for radiological assessment

- ${ }^{238} \mathrm{U},{ }^{226} \mathrm{Ra},{ }^{210} \mathrm{~Pb}$, and ${ }^{228} \mathrm{Ra}$ were retained very well, ${ }^{232} \mathrm{Th}$ and ${ }^{40} \mathrm{~K}$ leached out

- Drinking water is not endangered by leaching of NOR

- Different alkali activators substantially affected leaching of non-radiological elements 